\title{
Sharp Genant Joint Space Narrowing Score
}

National Cancer Institute

\section{Source}

National Cancer Institute. Sharp Genant Joint Space Narrowing Score. NCI Thesaurus.

Code C128987.

The numerical value that represents the result of a clinical assessment of joint space narrowing based on the Genant modification of the Sharp Joint Space Narrowing Assessment (Genant HK. Methods of assessing radiographic change in rheumatoid arthritis. Am J Med. 1983 Dec 30;75(6A):35-47). 